\title{
Presencia del enfoque intercultural en representaciones docentes sobre lo juvenil, la diversidad y la cultura rural
}

Presence of the intercultural approach in teaching representations on the youth, diversity, and rural culture

\section{Volumen 18, Número 3 \\ Setiembre-Diciembre}

pp. 1-18

\section{Este número se publica el 1 de setiembre de 2018}

DOI: https://doi.org/10.15517/aie.v18i3.34401

\author{
Carol Morales-Trejos
}

Revista indizada en $\underline{\text { REDALYC, SCIELO }}$

Revista distribuida en las bases de datos:

\section{LATINDEX, DOAJ, REDIB, IRESIE, CLASE, DIALNET, SHERPA/ROMEO, QUALIS-CAPES, MIAR}

Revista registrada en los directorios:

ULRICH'S $, \underline{R E D I E}, \underline{R I N A C E}, \underline{\text { OEI }}, \underline{\text { MAESTROTECA }}, \underline{\text { PREAL, }}$ 


\title{
Presencia del enfoque intercultural en representaciones docentes sobre lo juvenil, la diversidad y la cultura rural
}

Presence of the intercultural approach in teaching representations on the youth, diversity, and rural culture

\section{Carol Morales-Trejos ${ }^{1}$}

\begin{abstract}
Resumen: Este artículo científico presenta resultados del proyecto de investigación Prácticas Pedagógicas Docentes en Contextos de Interacción Juvenil Rural, de la Gran Área Metropolitana de Costa Rica: Una mirada desde la Educación Intercultural, inscrito al Instituto de Investigación en Educación (INIE) de la Universidad de Costa Rica en el periodo 2016-2017. Este escrito da cuenta, desde experiencias en educación rural a nivel de secundaria, de las representaciones docentes sobre lo juvenil, la diversidad, la cultura rural y de cómo estas se articulan en el quehacer profesional. A nivel metodológico, la investigación se sustenta en el enfoque hermenéutico-interpretativo, desde el cual se realizaron entrevistas en profundidad a 11 docentes de tres Liceos Técnicos Rurales de la Gran Área Metropolitana de Costa Rica. Se consideran resultados correspondientes al segundo y tercer objetivo específico de dicha investigación, asociados a "identificar las representaciones docentes sobre lo juvenil, la diversidad y la cultural rural, así como las nociones y principios del enfoque intercultural presentes en las prácticas pedagógicas estudiadas". Se señalan, dentro de los principales hallazgos, los criterios docentes respecto a los conceptos estudiados. Asimismo, se reconocen, en el accionar docente, aproximaciones interculturales desde la especificidad de los contextos, a nivel histórico y social, en los que dichas prácticas son realizadas. De manera específica, se muestran las representaciones que la persona profesional en educación posee, las cuales configuran una forma de conocimiento, a través de la cual, quien conoce, se coloca dentro de lo que conoce y actúa en consecuencia.
\end{abstract}

Palabras clave: educación, cultura, interculturalidad, joven rural.

\begin{abstract}
This scientific article presents results of the research project "Teaching Pedagogical Practices in Contexts of Rural Youth Interaction, of the Great Metropolitan Area of Costa Rica: a look from Intercultural Education" registered in the Institute of Investigations in Education (INIE) of the University of Costa Rica, in the 2016-2017 period. This paper gives an account of experiences in rural education at the secondary level of the teaching representations about youth, diversity and rural culture and how these are articulated in the professional work. At the methodological level, the research is based on the hermeneutic-interpretative approach, from which in-depth interviews were conducted with 11 teachers from three Rural Technical High Schools of the Greater Metropolitan Area of Costa Rica. This paper considers results corresponding to the second and third specific objectives of this research associated with "identifying teaching representations about youth, diversity and rural culture, as well as the notions and principles of the intercultural approach present in the pedagogical practices studied", pointing out within the main findings the breadth of teaching criteria regarding the concepts studied. Likewise, intercultural approaches are recognized in the teaching action from the specificity of the historical and social contexts in which said practices are carried out. Specifically, it shows the representation that the professional person in education, which forms a form of knowledge through which the person who knows is placed within what he knows and acts accordingly.
\end{abstract}

Key Words. education, culture, interculturality, rural youth.

\footnotetext{
${ }^{1}$ Docente e investigadora de la Universidad de Costa Rica, en la Escuela de Orientación y Educación Especial, Costa Rica. Doctora en Ciencias de la Educación, por la Universidad de Santiago de Chile.
}

Dirección electrónica: karolmoral@gmail.com

Artículo recibido: 2 de abril, 2018

Enviado a corrección: 15 de junio, 2018

Aprobado: 13 de agosto, 2018 


\section{Introducción}

En este artículo interesa mostrar la relación entre las representaciones docentes sobre lo juvenil, la diversidad y la cultura rural como estructuras cognitivas que configuran una forma de conocimiento, a través de la cual, quien conoce, en este caso, la persona docente, se coloca dentro de lo que conoce y actúa en consecuencia, (Jodelet citada por Bueno-Abad, 2000), y en ese actuar reconoce la presencia del enfoque intercultural.

Es un escrito que muestra parte de los datos recolectados del proyecto de investigación Prácticas Pedagógicas Docentes en Contextos de Interacción Juvenil Rural, de la Gran Área Metropolitana de Costa Rica: Una mirada desde la Educación Intercultural, Inscrito al Instituto de Investigaciones en Educación (INIE), abordado desde el campo de la educación intercultural. Por lo cual es clave, desde las nociones y principios del enfoque intercultural, según señala Abdallah-Pretceille (2006), rescatar lo intercultural como una práctica, en la medida en que la persona profesional presta menor atención a la cultura y más al sujeto que actúa y por lo tanto interactúa.

De igual manera, interesa evidenciar, según la autora, lo intercultural como una hermenéutica, haciendo énfasis en que ningún hecho es de entrada intercultural y dicha cualidad no es un atributo del objeto, solo el análisis intercultural puede conferirle este carácter, "es la mirada la que crea el objeto y no al contrario, lo intercultural reconstruye de la comprensión y de la acción el pensar, en el encuentro del Otro no como el producto del conocimiento, sino como un re-conocimiento" (Abdallah-Pretceille, 2006, p. 8).

A nivel metodológico, en relación con los escenarios, estos son contextos rurales que forman parte de la gran área metropolitana, zonas cafetaleras con un flujo migratorio importante en tiempos de cosecha. El estudiantado y sus familias siguen siendo caracterizados desde lo rural, como personas "humildes", "solidarias", "tranquilas", "con valores y tradiciones arraigadas", entre otros. El profesorado en su totalidad vive en contextos rurales, la mayoría, en el mismo en el que laboran, otros en zonas aledañas pero rurales, expresan una fuerte identificación en la educación rural.

El presente documento contiene los principales referentes teóricos que se sitúan a la base del análisis de los datos recolectados, una breve reseña de la metodología empleada, así como el análisis de los resultados que centran su atención en dar cuenta de los dos objetivos específicos a los que este artículo hace alusión, respecto a identificar las representaciones docentes sobre lo juvenil, la diversidad y la cultural rural, así como determinar las nociones y principios del enfoque intercultural presentes en las prácticas 
pedagógicas estudiadas, de las cuales se extraen dichas representaciones. Se finaliza con las principales conclusiones.

\section{Referentes teóricos}

\subsection{Representaciones sociales y prácticas pedagógicas}

El término representación social fue desarrollado por Moscovici aproximadamente entre los años 1961 y 1979, en su estudio sobre la representación social del psicoanálisis en la sociedad francesa. Las representaciones sociales, según Bueno-Abad (2000), se consideraron maneras de interpretar la realidad cotidiana a través de la actividad mental llevada a cabo por los individuos y los grupos, cuya finalidad es tomar posición respecto a situaciones, hechos, objetos y comunicaciones que les conciernen. Asimismo, son "formas de conocimiento socialmente elaboradas y compartidas, es a la vez el proceso de una actividad y la apropiación de la realidad, teniendo una visión práctica y concurrente a la construcción de una realidad común en un conjunto social" (Bueno-Abad, 2000.p.31).

De forma precisa, Araya (2002, p. 27) citando a Moscovici (1979), la representación social es:

un corpus organizado de conocimientos y una de las actividades psíquicas gracias a las cuales los hombres hacen inteligible la realidad física y social, se integran en un grupo o en una relación cotidiana de intercambios, liberan los poderes de su imaginación [...]

En este sentido, interesa señalar la relación en la lógica de organización de conocimientos y actividades, desde sus dimensiones cognitivas y sociales, dentro de la caracterización de las propias prácticas pedagógicas y de las representaciones de lo juvenil, la diversidad y la cultura rural del profesorado entrevistado en la investigación, de la cual se extraen los datos que presenta este artículo. Desde la teoría de las representaciones se planteó rescatar el pensar, el sentir y el hacer de la persona profesional en educación, inmersa en contextos educativos rurales. Interesó en la investigación, acorde con lo que plantea Araya (2002), identificar cómo las personas hacen referencia a los objetos sociales, los clasifican, los explican y, además, los evalúan.

Dichas representaciones, según Araya (2002), constituyen sistemas cognitivos en los que es posible reconocer la presencia de estereotipos, opiniones, creencias, valores y normas que suelen tener una orientación actitudinal positiva o negativa, que constituyen, a su vez, sistemas de códigos, valores, lógicas clasificatorias, principios interpretativos y 
orientadores de las prácticas que definen la llamada conciencia colectiva, la cual se rige con fuerza normativa por cuanto instituye los límites y las posibilidades de la forma en que las mujeres y los hombres actúan en el mundo. Aspectos claves que sitúan esta teoría como pertinente para analizar la comprensión de la persona docente en relación con sus saberes teóricos y pedagógicos en un contexto especifico como el rural.

De acuerdo con Araya (2002) retomando a Moscovici, el medio cultural en el que viven las personas, el lugar que ocupan en la estructura social y las experiencias concretas con las que se enfrentan a diario influyen en su forma de ser, su identidad social y la forma en que perciben la realidad social, en este sentido, la noción de realidad social y su proceso de construcción en un elemento clave para la comprensión de esta teoría y para acercarse a las prácticas pedagógicas.

Retomando los presupuestos epistemológicos y ontológicos del análisis de una representación social, de acuerdo con Araya (2002) es importante recalcar que el acceso al conocimiento de las representaciones se realiza por medio de un abordaje hermenéutico en el que el ser humano es visualizado como un productor de sentidos. En dicho abordaje se debe focalizar el análisis de las producciones simbólicas, de los significados y del lenguaje, a través de los cuales los seres humanos construyen el mundo en que viven. Es relevante plantear que conocer o establecer una representación social implica determinar qué se sabe (información), qué se cree, cómo se interpreta (campo de la representación) y qué se hace o cómo se actúa (actitud), dimensiones que deben ser estudiadas como partes de un conjunto (Araya, 2002).

Tras las consideraciones teóricas presentadas es importante recalcar que, desde la mirada intercultural, esta teoría constituye un gran aporte, pues permite comprender, mediante el análisis de las representaciones sociales, cómo la cognición y la interacción social influyen sobre el pensamiento y el comportamiento de los individuos implicados en la interacción, en este caso, el profesorado en relación con la diversidad, la juventud, la ruralidad y la cultura.

Asimismo, el reconocimiento de las representaciones sociales que median las prácticas pedagógicas, objeto de estudio de la investigación a la que se hace referencia, permiten, como plantea Villarroel (2007, p. 441), reconocer que en cualquier acto de representación se da una actividad constructiva y reconstructiva por parte del sujeto.

El abordaje de las representaciones sociales posibilita, entonces, comprender la dinámica de las interacciones sociales y aclarar los determinantes de las prácticas sociales, pues la representación, el discurso y la práctica se generan mutuamente, (Banchs, 1991 citada por Araya, 2002, p.12). Se deriva, además, que la importancia de conocer, desentrañar y cuestionar el núcleo figurativo de una representación social, alrededor del cual 
se articulan creencias ideologizadas, constituye un paso significativo para la modificación de una representación y, por ende, de una práctica social, como lo son las prácticas pedagógicas.

\subsection{Interculturalidad en el contexto educativo: Una Aproximación conceptual y práctica}

Al referirnos a la interculturalidad no podemos dejar de lado el hablar acerca del surgimiento del multiculturalismo, esto debido a que tanto el origen discursivo como práctico de la interculturalidad se sustenta en muchos de sus planteamientos. Dietz (2003) señala los orígenes del multiculturalismo en un abanico amplio de movimientos sociales de los años sesenta y setenta, los cuales buscaban un horizonte político-social común. Estos movimientos, según el autor, surgen en el seno de las sociedades crecientemente postindustriales levantadas contra la institucionalidad establecida del Estado-nación, y es, desde estos procesos de institucionalización programática, que los movimientos multiculturalistas van generando su propia teorización académica, sobre todo para el contexto anglosajón (Dietz, 2003).

Autores como Taylor (1993) y Habermas (2002) integran el debate multicultural, sus aportes se basan en la lucha por este reconocimiento de la diferencia, de la diversidad cultural, que al día de hoy sigue siendo trasladado a otras realidades sociales, educativas y políticas, dada su pertinencia, la cual, como señala Torres (2001), radica en constituir temas como democracia, ciudanía y educación, los cuales no pueden tratarse aislados del tema del multiculturalismo.

Dietz 2012 considera que, en los años noventa, tanto los orígenes como los aspectos discursivos del multiculturalismo y de la interculturalidad comienzan a separarse, y surgen algunas diferencias en el plano fáctico y normativo. La perspectiva intercultural comparte con el multiculturalismo el respeto hacia la diferencia y el hecho de instaurar la diversidad cultural como escenario de interacción para el enriquecimiento mutuo. Bajo esta premisa, se plantean enormes retos ciudadanos a fin de comprender adecuadamente la diversidad del ser humano y la comunicación intercultural en el contexto de las sociedades actuales. La educación intercultural propone, según Sagastizabal, Perlo, Pivetta y San Martin (2009, p.75). "una mirada de la pluralidad cultural como una riqueza, aprecia el mundo de lo humano, en el mundo de la cultura, su pluralidad de expresiones, las valora como una sobreabundancia".

Muy acorde con Dietz (2003), para Aguado (1995), la educación intercultural, no es: 
- Celebrar aisladamente las diferencias, por ejemplo, las llamadas "semanas interculturales", "días gastronómicos", "días de la Paz", etc.

- Clasificar a determinados grupos como "los otros" y eludir la posibilidad de conocerlos mejor en un plano de igualdad.

- Buscar recetas para solucionar problemas o para dirigirse a los grupos clasificados como "los otros".

- Confeccionar programas educativos aislando grupos específicos, como ocurre en las clases compensatorias.

- Tratar de incluir en clase a estudiantes de distintos orígenes sin promover activamente relaciones positivas con ellos.

- Evitar conflictos, los conflictos son parte de nuestra vida cotidiana, de lo que se trata es de manejarlos apropiadamente, ser conscientes de nuestros sesgos y aprender activamente a luchar contra la discriminación y los prejuicios que todos empleamos a diario.

Acciones concretas que tienden a llevarse a cabo dentro de los contextos educativos bajo el nombre de educación intercultural, prácticas pedagógicas interculturales o bien pedagógica intercultural, pero que se sustentan en discursos como los planteados por Dietz (2003). De igual manera, siguiendo planteamientos como los de Leiva (2011) y Rehaag (2010), se puede comprender que no corresponden a una genuina intervención intercultural, por el contrario, son acciones educativas que ubican la interculturalidad en una encrucijada, que va desde la exaltación folclórica de las culturas del estudiantado de origen inmigrante y/o indígena al enfoque curricular compensatorio (Leiva, 2011).

De acuerdo con Aguado (1995, p. 16), cabe precisar que la educación intercultural es, por lo tanto:

un enfoque educativo basado en el respeto y apreciación de la diversidad cultural. Se dirige a todos y cada uno de los miembros de la sociedad en su conjunto, propone un modelo integrado de actuación que afecta a todas las dimensiones del proceso educativo. Se aspira a lograr una auténtica igualdad de oportunidades/resultados para todos; así como la superación del racismo en sus diversas manifestaciones y el desarrollo de competencias interculturales en profesores y estudiantes

Al considerar la interculturalidad como un enfoque que permite comprender la realidad educativa desde otras lógicas, cabe plantearse qué significa enseñar hoy, considerando 
escenarios tan diversos como los actuales. Desde la mirada intercultural, enseñar hoy no es desechar enfoques y/o paradigmas que han dado lugar a lo que hoy es la Escuela, sino integrar saberes, potenciar la diversidad sociocultural, articular los espacios educativos (escuela) y la comunidad, o bien, en contextos rurales, articular espacios y territorios desde una mirada crítica-transformadora, esto configura el reto educativo contemporáneo. Para Abdallah-Pretceille (2006), la educación intercultural funge como hermenéutica, es decir, permite agenciar mecanismos teóricos y prácticos para su comprensión. A continuación, se retoman 2 de los 5 postulados de la autora (Abdallah-Pretceille, 2006, pp. 1-9), que permiten comprender lo intercultural de forma teórico-práctica, a saber:

\section{Lo intercultural es una práctica}

En la medida en que la persona profesional presta más atención al sujeto que actúa y, por lo tanto, interactúa. No se trata de buscar hipotéticas realidades culturales, señala la autora, sino, al contrario, de aprender una forma de práctica cultural, de comprender cómo se crea lo cultural en situaciones complejas. Desde la perspectiva intercultural, la intervención docente se debe detener menos sobre la cultura como determinante de los comportamientos, que sobre la manera en la que el individuo utiliza los rasgos culturales para decir y decirse, para expresarse verbalmente, corporalmente, socialmente, personalmente.

\section{Lo intercultural es una hermenéutica}

En este punto es importante recalcar que ningún hecho es de entrada intercultural y dicha cualidad no es un atributo del objeto, solo el análisis intercultural puede conferirle este carácter, "es la mirada la que crea el objeto y no al contrario, lo intercultural reconstruye de la comprensión y de la acción el pensar en el encuentro del Otro no como el producto del conocimiento sino como un re-conocimiento" (Abdallah-Pretceille, 2006, p. 8).

Situar el aporte de la interculturalidad a nivel educativo es clave, Escarbajal (2010) plantea que la educación intercultural puede significar una buena alternativa a los modelos educativos monoculturales, porque, frente a la perpetuación de la cultura única, acepta la complejidad de cada ser humano y de su cultura, reconoce que todos somos pluriculturales y podemos trabajar juntos para conseguir una sociedad democrática. En este sentido, la interculturalidad connotaría no solo el reconocimiento a nivel socioeducativo de la existencia de grupos culturales distintos, sino también de inter-relaciones en planos diversos en igualdad, sustentados en el mutuo respeto. Por ende, la interculturalidad correspondería a una aspiración como proyecto nacional a nivel sociopolítico. 


\section{Metodología}

A nivel metodológico, la investigación se sustenta en el enfoque hermenéuticointerpretativo, desde el cual se realizaron entrevistas en profundidad a 11 docentes de tres Liceos Técnicos Rurales de la Gran Área Metropolitana de Costa Rica, a cada persona educadora se le realizaron tres entrevistas individuales y estructuradas que permitieron, a la persona investigadora, conocer el accionar docente y las representaciones a las que este artículo hace referencia. Cabe señalar que las tres representaciones que este articulo presenta son referidas por el profesorado entrevistado a lo largo de las tres entrevistas realizadas (no de observaciones), en las que se les solicitó información respecto a cómo hacían su clase, para ello se consideraron los 5 componentes operativos de las prácticas pedagógicas, los cuales son diagnóstico, contextualización, planeamiento, mediación pedagógica y evaluación.

Desde este paradigma metodológico, la visión de la realidad es múltiple, su enfoque es expansivo, se considera en el proceso de investigación el descubrimiento, la comprensión y la interpretación participativa, es la persona investigadora el instrumento privilegiado (Erazo, 2012). Se retoma, además, dentro de esta metodología un diseño de investigación etnometodológico, caracterizado por la flexibilidad y la multiplicidad de escenarios y/o actores sociales que abarca, ya que corresponde a un estudio que selecciona un número menor de aspectos del fenómeno en estudio aplicado a un número mayor de actores sociales dentro del fenómeno (Erazo, 2012).

Este proyecto de investigación abarcó 3 Liceos rurales ubicados dentro de la Gran Área Metropolitana, específicamente en las provincias de San José y Alajuela en Costa Rica, cuya modalidad correspondiera a educación técnica diurna pública rural (Tabla 1). De manera específica se entrevistaron a 11 personas docentes ( 6 hombres y 5 mujeres), nueve de asignaturas básicas y dos de especialidad técnica, todas ellas con grado de licenciatura y otras personas con algunas especialidades a nivel de diplomados (Tabla 2).

Los criterios de selección de las personas docentes participantes en el estudio fueron:

1. Profesionales de educación (distintas áreas del currículum).

2. Docentes guías de décimo o undécimo año.

3. Que laboraran en los establecimientos educativos seleccionados públicos, rurales y técnicos.

4. Pertenecientes a la comunidad rural donde se ubica el Liceo o una comunidad rural cercana. 
Tabla 1. Descripción de los centros educativos y personas participantes del estudio, 2016-20174

\begin{tabular}{|l|l|l|l|c|}
\hline Provincia & Cantón & $\begin{array}{c}\text { Nombre del establecimiento } \\
\text { educativo }\end{array}$ & $\begin{array}{l}\text { Número de docentes } \\
\text { por centro educativo }\end{array}$ & $\begin{array}{c}\text { Cantidad de } \\
\text { entrevistas }\end{array}$ \\
\hline \multirow{2}{*}{ San José } & Dota & $\begin{array}{l}\text { C.T.P José Daniel Flores } \\
\text { Zavaleta. }\end{array}$ & $\begin{array}{l}5 \text { docentes } \\
(3 \mathrm{M} / 2 \mathrm{H})\end{array}$ & 15 \\
\cline { 2 - 5 } & Acosta & C.T.P de Palmichal. & $\begin{array}{l}3 \text { docentes } \\
(2 \mathrm{M} / 1 \mathrm{H})\end{array}$ & 9 \\
Alajuela & Naranjo & C.T.P El Rosario. & $\begin{array}{l}3 \text { docentes } \\
(3 \mathrm{H})\end{array}$ & 9 \\
\hline
\end{tabular}

Fuente: Elaboración propia, 2017

Tabla 2. Características de las personas participantes en el proyecto, 2016-2017

\begin{tabular}{|c|c|c|c|c|c|}
\hline $\begin{array}{c}\text { Código } \\
\text { docente }\end{array}$ & Sexo & edad & $\begin{array}{c}\text { Origen } \\
\text { geográfico }\end{array}$ & $\begin{array}{c}\text { Grado } \\
\text { académico }\end{array}$ & $\begin{array}{c}\text { Años de } \\
\text { experiencia }\end{array}$ \\
\hline PCTPZ1 & $\mathrm{M}$ & 32 & Rural & Licenciatura & 11 años \\
\hline PCTPZ2 & $\mathrm{H}$ & 33 & Rural & Licenciatura & 10 años \\
\hline PCTPZ3 & $\mathrm{M}$ & 32 & Rural & Licenciatura & 10 años \\
\hline PCTPZ4 & $\mathrm{H}$ & 27 & Rural & Licenciatura & 8 años \\
\hline PCTPZ5 & $\mathrm{M}$ & 48 & Rural & Licenciatura & 23 años \\
\hline PCTPR1 & $\mathrm{H}$ & 34 & Rural & Licenciatura & 15 años \\
\hline PCTPR2 & $\mathrm{H}$ & 37 & Rural & Licenciatura & 3 años \\
\hline PCTPR3 & $\mathrm{H}$ & 27 & Rural & Licenciatura & 5 años \\
\hline PCTPP1 & $\mathrm{M}$ & 27 & Rural & Licenciatura & 8 años \\
\hline PCTPP2 & $\mathrm{M}$ & 29 & Rural & Licenciatura & 8 años \\
\hline PCTPP3 & $\mathrm{H}$ & 37 & Rural & Licenciatura & 14 años \\
\hline
\end{tabular}

Fuente: Elaboración propia, 2017

\footnotetext{
${ }^{4}$ En los respectivos consentimientos informados se especifica que al dar a conocer resultados de la investigación se emplearían seudónimos para el profesorado, no así a nivel Institucional.
} 
En lo que respecta al procedimiento de análisis y validación de la información recolectada, para los propósitos de la investigación citada, se empleó el análisis de contenido, el cual, según Delgado y Gutiérrez (2007), es un tipo de análisis cualitativo que se centra en el análisis de las expresiones verbales tanto orales como escritas. Por su parte, Cáceres (2003, pp. 58-68) establece una serie de pasos en el procedimiento de análisis de contenido que este proyecto de investigación consideró de manera rigurosa en cuatro etapas, a saber: el ajuste tabla de consistencia (formulación categorías y sub categorías de análisis), la codificación progresiva (uso de tablas descriptivas), el análisis descriptivo (diferentes niveles) y el análisis interpretativo (conclusiones y proyecciones investigativas).

\section{Análisis de resultados}

\subsection{Presencia del enfoque intercultural en las representaciones docentes}

A continuación, se precisan las representaciones docentes sobre lo juvenil, la diversidad y la cultura rural haciendo referencia al saber, la información (reconocimiento), lo que se cree, cómo se interpreta (valoración) y qué se hace o cómo se actúa (incorporación), dimensiones que son estudiadas como partes de un conjunto vinculado al enfoque intercultural. Sobre la representación de lo juvenil, es relevante señalar elementos que se aproximan a principios de la interculturalidad considerados por todo el profesorado entrevistado, como la sensibilidad y/o disposición docente hacia la comprensión del mundo juvenil, sobre todo en lo que se relaciona con las diversas problemáticas que vivencian las personas jóvenes a nivel personal, familiar y socioeconómico.

El favorecer espacios dentro de la sala de clase para el trabajo colaborativo, la escucha, el diálogo, el debate de ideas e intercambio de opiniones, el basar la interacción docente-estudiante en la confianza y el respeto son aspectos que se vinculan de forma concreta con principios de la educación intercultural, esto según los planteamientos de autores como Aguado y Del Olmo (2009), Leiva, (2011) y Sagastizabal et al. (2009) y permiten, siguiendo a Duarte (2012) y a Grosser (2003), superar el conflicto intergeneracional y construir "puentes" entre el mundo juvenil y el adulto.

Un factor que favorece la construcción de estos puentes lo configura el agrado docente por lo que se hace, es decir, por enseñar, ejemplo de ello se puede evidenciar con lo señalado por PCTPR1 "yo le puedo decir que yo hago las cosas con el corazón, yo de verdad les doy clases a ellos con el corazón", y lo que menciona PCTPR2 "eso es una parte 
muy bonita, muy humana, ese acercamiento con los jóvenes y poder transmitirles conocimientos, también proveerles de alguna u otra manera, transmitirles la experiencia de vida de uno".

Respecto al reconocimiento de lo juvenil, el profesorado señala como elementos que caracterizan a las personas jóvenes, principalmente y de manera coincidente, la humildad, el ser tranquilos y procedentes de familias muy trabajadoras y con escasos recursos, que limitan el acceso a la tecnología y al conocimiento. Muchas de las personas jóvenes en época de cosecha del café principalmente, trabajan en recolección, ya que en los tres contextos estudiados se da el cultivo del café. Señala PCTPR1; " hacen un esfuerzo por salir muchas veces de la pobreza, y que encuentra en la educación la única arma para salir adelante porque muchas veces son hijos de peones, o que tienen algún terreno pero ahora la agricultura no representa una forma de ingreso para vivir entonces ellos ven en la educación como conseguir un ingreso y poder ayudar a sus familias o para salir ellos adelante".

Es importante señalar que el profesorado entrevistado define lo juvenil en contextos rurales desde características personales/individuales de las personas jóvenes, así como contextuales, culturales, relacionales y familiares. Además, hacen referencia a necesidades, diferencias entre jóvenes rurales y urbanos, gustos y preferencias, construcciones que se asocian a planteamientos de Duarte (2000) y Zabadúa (2008), por cuanto corresponden a un conjunto de significaciones construidas de lo juvenil que responden a una multiplicidad de referentes que se ponen en interacción en distintos espacios sociales contemporáneos, en este caso, el escolar, familiar y personal.

La valoración de lo juvenil en territorios rurales, es muy positiva, ya que pensar desde un lugar posibilitador a las personas jóvenes, permite conceptualizar a las juventudes desde otras lógicas, que adquieren sentido dentro de un contexto social más amplio y en su relación con lo no juvenil, aspecto que se vincula con las hetero-representaciones elaboradas por agentes o instituciones sociales externas a las personas jóvenes y las autorepresentaciones de las mismas personas jóvenes.

Desde la práctica pedagógica, en lo que respecta a la incorporación de lo juvenil, esta se hace desde referentes cognitivos, gustos y preferencias de las personas jóvenes en el planeamiento didáctico. PCTPP1 señala "yo siempre he buscado como que ninguno se sienta fuera de, que no sean trabajos tan rígidos porque no todos tienen las mismas posibilidades". Por su parte, PCTPP2 menciona "eso hacemos dinámicas en el aula, que no 
sea todo tan aburrido sino que lo que hacemos es que leemos el folleto al final trato de hacerles un resumen general de lo que hemos visto para ver que tanto han aprendido y trato de enfocárselos en la vida cotidiana, en el trabajo".

La diversidad es entendida como la convivencia de distintas formas de ser, de pensar, de vivir, de creer definida por el profesorado, muestra un largo itinerario de desafíos por asumir desde la propuesta intercultural; por ejemplo, PCTPR1 expresa que "todos los estudiantes son diferentes piensan y actúan diferente, entonces tenemos una diversidad en el aula increíble, entonces es probable que inclusive cuando uno explica un tema o un contenido lo está trabajando, que algunos lo estén entendiendo y otros no, porque todos tienen formas de pensar diferentes, formas de aprender diferentes; todos son tan diferentes".

En concordancia con las consideraciones de Hernández (2002, citada por Aguado y Del Olmo, 2009), es relevante, en cuanto a la diversidad, reconocer, en un primer momento, que existe diversidad en cada ser humano; en un segundo nivel, conocer el significado de la diversidad y el valor social que les confiere el contexto social; y en tercer lugar, apreciar la diversidad de forma positiva, indistintamente del valor que el grupo social le confiera a unas u otras diferencias. En este último nivel, pese a que se articulan discursos posibilitadores, aún hace falta trabajar desde la reflexión y la criticidad, formas de hacer que dicho reconocimiento y valoración sean una realidad en la práctica pedagógica, sobre todo en lo que respecta a la diversidad sexual.

Pese a lo anterior, es interesante resaltar, tras el relato docente, dos planteamientos críticos que generan una reflexión importante por cuanto desde la mirada intercultural se han empleado para tensionar viejos y nuevos paradigmas en torno a la diversidad. El primero de ellos "potenciar más la diversidad que las diferencias", lo cual se evidencia en argumentos como los de PCTPP3, "aceptar la diversidad es saber que todos tenemos un origen común pero distinto, más esta comunidad que recibe muchos migrantes...yo le digo eso que eso es parte de una sociedad, la diversidad, que eso se forma en la sociedad. $Y$ tener un pensamiento no tan cerrado porque a veces los chiquillos por su entorno familiar a veces se cierran mucho en un pensamiento".

Según las consideraciones de Abdallah-Pretceille (2006), la segunda lo constituye el no "emplear la diversidad como etiqueta", ya que, por el contrario, se deben generar procesos que favorezcan el aprendizaje desde las potencialidades de cada estudiante, menciona PCTPZ1 "por ejemplo la diversidad en los estilos de aprendizaje, la diversidad ritmo de aprendizaje eso hay que saberlo manejar, dejando de lado lo que es una adecuación 
significativa, que sí definitivamente no le podemos ver ventajas o cuesta mucho verlo pero en el mismo grupo en el mismo nivel, con los mismos objetivos más bien eso enriquece el aprendizaje porque yo estoy explicando entonces yo siempre les pregunto, si lo resolvieron, cómo lo resolvieron y si alguien lo resolvió diferente, el simple hecho de permitirles que se expresen, aunque a veces se equivocan uno los corrige de forma agradable por ejemplo, si favorece".

Otras aproximaciones a los principios interculturales que se pueden identificar en el discurso docente vinculan diversidad con riqueza, pertenencia e identidad, señalamientos muy acordes con los planteamientos de Torres (2001) y Femenías (2007), relevantes en la formación de una ciudadanía crítica que aprecie tanto lo propio como lo ajeno, lo rural y lo urbano, las similitudes y las diferencias como referentes que enriquezcan nuestras interacciones. Tras los discursos docentes en torno a las representaciones, y desde lo que cada persona comenta hacer en su práctica pedagógica, el abordaje de la diversidad, lo juvenil en contextos rurales y la cultural rural como tal.

Para avanzar de un plano de reconocimiento y valoración a nivel cognitivo, por parte del profesorado, tras el análisis de sus discursos, a un nivel de incorporación genuino hace falta agenciar procesos de actualización o de formación inicial docente desde la mirada intercultural. Según Guidetti (2005, citado por Escarbajal, 2010, p.144), esto implicaría desde la práctica educativa "recoger la multiculturalidad para transformarla en encuentro rico y formativo entre los estudiantes... si como una educación que transforme los estereotipos negativos y los prejuicios en actitudes positivas hacia el encuentro y la fusión con otras culturas", noción clave dentro de la intervención intercultural, y que no se articula desde lo que la persona educadora dice y hace en su práctica docente.

Sobre cultura, es importante mencionar que se conceptualiza de manera amplia, en cuyo constructo se reconoce y valora la importancia de rescatar la cultura rural desde los valores, tradiciones y costumbres que crean identidad y pertenencia con lo rural, señalamientos que unen lo rural y lo cultural en cultura rural. PCTPP1 señala que es "conjunto de características que tenemos por pertenecer a algún lugar específico y lógicamente que tiene que ir acompañado de las tradiciones, costumbres y los principios que se han ido con el pasar del tiempo, de los que traían mis abuelos y que ahora se han ido fortaleciendo".

De igual manera PCTPP2 refiere a la cultura rural "como todas las capacidades, toda la parte que tiene un estudiante ya sea diversidad, costumbres, tradiciones, es absolutamente 
todo lo que trae consigo el estudiante, es lo que va caracterizar a Palmichal de otros lugares", por su parte "son todas las acciones que una persona pueda realizar dentro de un contexto, involucra arte, involucra tradiciones, involucra producción, costumbres, incluso el tema culinario" (PCTPP3).

Estos factores, nos permiten ir aprendiendo a descubrir el valor de lo diferente para reducir la desigualdad. Sin embargo, en un plano más operativo hace falta realizar el salto hacia el rescate de la identidad rural, es decir, reconocer, valorar e incorporar en los espacios educativos y, precisamente, desde las prácticas pedagógicas, los distintos posicionamientos en y sobre el mundo que se genera desde lo rural como cultura.

La representación de todas las personas docentes sobre cultura, principalmente, hace referencia a elementos asociados a la comunidad, las tradiciones y costumbres que la definen a nivel colectivo, pero también a nivel individual, señala PCTPR1 "el conjunto de costumbres y tradiciones que caracterizan a una región o población”, elementos que lleva a plantearse el constructo de cultura rural.

De manera específica, la cultura rural es entendida desde lo que diferencia lo urbano de lo rural, "siento que son una cultura rural, el hecho de que ellos no tengan a la mano todo lo que es la ciudad y lo que expone la sociedad sino solo parte de ello... un muchacho que viva en la ciudad siempre va a tener internet porque en todos los lugares hay wifi, aquí (nombre el pueblo) ellos sólo tienen wifi" (PCTPR1).

Se reconoce, además, el territorio rural como un buen lugar para vivir, no así para formarse académicamente. Como señala Kessler (2005), las limitaciones en las oportunidades educativas y laborales hacen aparición en el discurso docente para señalar que sí, actualmente, las personas jóvenes desean continuar con sus estudios o acceder a otros empleos deben de migrar a la cuidad, aspecto que tensiona la vivencia en estos espacios. En cuanto a la ruralidad, muy acorde con los planteamientos sobre cultura rural, se identifica una actitud docente que tiende a valorar la vida que se desarrolla en los espacios rurales, se valoran las raíces, tradiciones y costumbres como una riqueza, la cual se contrapone con la opinión sobre la vida en los espacios urbanos, manteniéndose la dicotomía campo-cuidad y además, la influencia de un espacio sobre el otro, predominio que tiende a percibirse negativamente.

Es importante hacer mención a la representación docente sobre educación rural, ya que se vincula con espacios de posibilidades y de limitaciones para lo juvenil en contextos rurales por cuanto está marcada por una serie de debilidades y fortalezas. Entre las 
debilidades se encuentran: el disponer de muy pocos recursos a nivel institucional y las escasas o nulas oportunidades laborales para el estudiantado en la zona/comunidad después de concluir sus estudios técnicos.

PCTPR3 al referirse a lo rural, hace mención a lo que él denomina "ciudades dormitorio" añadiendo que "es un término relativamente nuevo, que es que todo el Occidente las personas duermen aquí, pero ellos trabajan en el GAM... porque las fuentes de empleo no hay.... hay personas que se han puesto una pulpería, es un negocio propio...el que tiene chapulines trabaja con la caña y el que quiere trabajar cortando caña y café, y listo..."

Respecto a las fortalezas de la educación rural, el profesorado, de manera coincidente, señala, para los tres contextos educativos, que el ser un colegio rural y técnico constituye una herramienta hacia el futuro de las personas jóvenes, solo que para conseguir trabajo deben de salir de la zona. El impartirse en modalidad nocturna en uno de los colegios, la oferta técnica es otra fortaleza señalada, el poder generar una enseñanza personalizada dado el poco número de estudiantes, la participación en actividades como el Festival de las Artes y concursos a nivel regional y nacional, los valores que aún se conservan en la comunidad y la educación rural son relevantes en la educación ciudadana, que el profesorado señala como aspectos positivos de la educación rural.

PCTPR3 destaca que a pesar de que el colegio es relativamente nuevo, el estudiantado "está empezando a tirarse hacia afuera a concursos, a concursar en el Festival de las Artes, a concursar en ferias científicas, robótica" y demás actividades estudiantiles que han venido a fortalecer la identidad del estudiantado en Colegios Técnico Profesionales. La educación técnica es considerada por el profesorado como una herramienta para que puedan seguir estudiando, "al estudiante le va a ayudar mucho, pero siempre digo que siga estudiando, que no se quede ahí, siga estudiando más allá...”.

En los contextos rurales el profesorado reitera que aún se conservan valores, señala CTPR3 que "aún se mantienen los valores, aún se mantiene la estructura de la familia, de la amistad, y eso es muy fuerte, entonces es algo muy positivo..." lo cual es señalado como una fortaleza de la Educación rural.

\section{Conclusiones}

Las representaciones docentes sobre lo juvenil, la diversidad y la cultura rural, constituyen efectivamente sistemas cognitivos en los que es posible reconocer la presencia de estereotipos, opiniones, creencias, valores y normas que suelen tener una orientación 
actitudinal. Es decir, lo que se cree respecto a las representaciones, en términos de reconocimiento y valoración, guarda estrecha relación en su incorporación dentro de las prácticas pedagógicas estudiadas. Los acercamientos al enfoque intercultural se basan principalmente en el reconocimiento de la diversidad en el espacio educativo, como riqueza que supone desafíos docentes importantes para poder avanzar a su pertinente incorporación, la cual representa un aspecto a seguir estudiando y fortaleciendo en la formación inicial docente, así como en procesos de actualización profesional.

Se identifica una actitud docente que tiende a valorar la vida que se desarrolla en los espacios rurales, se valoran las raíces, tradiciones y costumbres, aspecto importante de considerar desde la mirada intercultural. Sin embargo, parte de esta mirada no trasciende a cuestionamientos críticos del referente cultural, lo cual representa un punto de trabajo con el profesorado en formación inicial, o bien, que laboren en contextos rurales. De manera específica, respecto a las representaciones de lo juvenil, la diversidad y la cultura rural, se da una valoración situada desde la comparación constante entre lo rural y lo urbano, entre características deseadas y otras no tan deseadas, mediadas por estereotipos hacia el otro, aspectos que requieren de un mayor estudio, y pueden considerarse líneas investigativas a seguir desarrollándose.

A nivel conductual, en lo que respecta a la incorporación de las representaciones en la práctica pedagógica, cabe señalar que se evidencia un vacío en el cómo dar cuenta de manera operativa, en el acto pedagógico, de la diversidad de referentes culturales que poseen tanto las personas jóvenes, con las cuales interactúan, como el contexto rural en el que se sitúan los centros educativos y sus familias.

Desde las posibilidades de la educación intercultural, en el contexto educativo, las representaciones docentes, y cómo estas se relacionan con la práctica docente, ha permitido situar claves para seguir reflexionando, investigando y sobre todo generar procesos de capacitación y formación docente que permitan articular de una manera más pertinente la diversidad contextual, social y cultural que poseen las personas jóvenes en territorios rurales.

Este estudio pretende sentar las bases para posteriores investigaciones, en el mejor de los casos, investigación-acción, que permita formar al profesorado en competencias interculturales y registrar, así, la realización de prácticas pedagógicas interculturales partiendo de una intencionalidad clara y propositiva desde dicha mirada. 


\section{Referencias}

Abdallah-Pretceille, M. (2006). El paradigma intercultural como mirada hacia la diversidad. Actas Congreso INTER. Madrid, España: Publicaciones UNED. Intercultural. Recuperado de http://www.uned.es/congreso-inter-educacion-intercultural

Aguado, María Teresa. (1995). Un modelo de Orientación para la comprensión y competencia multiculturales. Revista Española de Orientación y Psicopedagogía, 6(10), 105-111.

Aguado, Teresa y Del Olmo, Margarita. (2009). Educación Intercultural. Perspectivas y propuestas. Madrid, España: Editorial Universitaria Ramón Areces, Universidad Nacional Educativa a Distancia (UNED).

Araya, Sandra. (2002). Las representaciones sociales: Ejes teóricos para su discusión. San José, Costa Rica: Facultad Latinoamericana de Ciencias Sociales (FLACSO) Sede Académica.

Bueno-Abad, José. (2000). Concepto de representaciones sociales y exclusión. Valencia, España: Facultad De Ciencias Sociales Universidad de Valencia.

Cáceres, Pablo. (2003). Análisis Cualitativo de Contenido: Una alternativa metodológica alcanzable. Revista Psicoperspectivas, 2(1), 53-82.

Dietz, Gunter. (2003). Multiculturalismo, interculturalidad y educación. Una aproximación antropológica. Granda, España: Editorial Universidad de Granada.

Dietz, Gunter. (2012). Multiculturalismo, interculturalidad y diversidad en educación: una aproximación antropológica. México: FCE.

Duarte, Klaudio. (julio, 2012). Sociedades adultocéntricas: sobre sus orígenes y reproducción. Revista Última Década, (36), 99-125.

Duarte, Klaudio. (Septiembre, 2000) ¿Juventud o juventudes? Acerca del como mirar y remirar a las juventudes de nuestro Continente. Revista Última Década, (13), 59-77.

Delgado, José Manuel y Gutiérrez, Juan. (2007). Métodos y técnicas cualitativas de investigación en ciencias sociales. Madrid: Síntesis.

Erazo, Soledad. (2012). Prácticas reflexivas, racionalidad y estructura en contextos de interacción profesional. Perfiles educativos, 33(133), 114-133. Recuperado de http://www.redalyc.org/pdf/132/13219088007.pdf

Escarbajal, Andrés. (2010). Interculturalidad, Medición y trabajo colaborativo. Madrid, España: NARCEA, S.A.

Femenías, María de los Ángeles. (2007). El género del multiculturalismo. Buenos Aires, Argentina: Universidad de Quilmes.

García, Néstor. (2004). ¿Ser diferentes es desconectarse? Sobre las culturas juveniles. En Néstor García, Diferentes, desiguales y desconectados (pp. 167-180). Barcelona: Editorial Gedisa. 
Grosser, Kattya. (2003). Adolescentes y adultos ¿Es posible una interacción sin juzgar ni castigar?, ¿Qué hay detrás del llamado conflicto generacional? Actualidades Investigativas en Educación, 3(1), 1-13. Recuperado de https://revistas.ucr.ac.cr/index.php/aie/article/view/9006/17453

Habermas, Jünger. (2002). La inclusión del otro. Estudios de teoría política. Barcelona, España: Paidós.

Jodelet. Denise. (1986). La representación social: fenómenos, conceptos y teoría. En Serge Moscovici, Psicología social II. Pensamiento y vida social, pensamiento y problemas sociales (pp. 469-495). Barcelona: Paidós.

Kessler, Gabriel. (2005) Estado del Arte de la Investigación Sobre Juventud Rural en América Latina. Recuperado de http://juventudruralemprendedora.procasur.org/wpcontent/uploads/2013/08/060100-Estado-del-arte-de-la-investigacio\%CC\%81n-sobreJuventud-Rural-Kessler.pdf

Leiva, Juan. (marzo, 2011). La Educación Intercultural en una encrucijada de caminos: reflexiones pedagógicas para la construcción de una escuela intercultural. Revista digital del centro del profesorado Cuevas-Olula (Alemeria). Espiral. Cuadernos del profesorado. 7(4), 43-56.

Rehaag, Irmgard. (marzo-abril, 2010). La perspectiva Intercultural en la Educación. El Cotidiano, (160), 75-83. Recuperado de http://www.redalyc.org/pdf/325/32512766009.pdf

Sagastizabal, María de los Ángeles, Perlo, Claudia, Pivetta, Bibiana, San Martin, Patricia. (2009). Aprender y enseñar en contextos complejos. Multiculturalidad, diversidad y fragmentación. Buenos Aires, Argentina: Centro de Publicaciones Educativas y material didáctico.

Schmelkes, Silvia. (2002). La enseñanza de la lectura y la escritura en contextos multiculturales. Conferencia presentada en el VII Congreso Latinoamericano para el Desarrollo de la Lectura y la Escritura, del 16-19 octubre, Puebla, México.

Taylor, Charles. (1993). El multiculturalismo y la política del reconocimiento. México D.F. FCE.

Torres, Carlos. (2001). Democracia, educación y multiculturalismo: dilemas de la ciudadanía en un mundo global. México D.F.: Siglo XXI.

Villarroel, Gladys. (mayo-agosto, 2007). Las representaciones sociales: una nueva relación entre individuo y sociedad. FERMENTUM, Revista Venezolana de Sociología y Antropología, 17(49), 434-454.

Zabadúa, Juan Pablo. (2008). Culturas Juveniles en contextos globales. Estudio sobre la construcción de los procesos identitarios de las juventudes contemporáneas (Tesis para optar por el grado de Doctor en el programa de Sociedades Multiculturales y Estudios Interculturales). Universidad de Granada, España y Universidad de Xalapa, Veracruz, México. 